\title{
Smoking cessation and COPD: further evidence is more necessary than ever
}

\author{
Lucy Wood $^{1}$, Jennifer K. Quint ${ }^{2}$ and Joan B. Soriano $\mathbb{1}^{3,4}$
}

\begin{abstract}
Affiliations: ${ }^{1}$ Public Health England Field Epidemiology Service, Institute of Public Health, Cambridge, UK. ${ }^{2}$ Respiratory Epidemiology, Occupational Medicine and Public Health, Imperial College London, London, UK. ${ }^{3}$ Instituto de Investigación Hospital Universitario de la Princesa (IISP), Universidad Autónoma de Madrid, Madrid, Spain. ${ }^{4}$ Scientific and Methodological Consultant, Sociedad Española de Neumología y Cirugía Torácica (SEPAR), Spain.
\end{abstract}

Correspondence: J. B. Soriano, Instituto de Investigación Hospital Universitario de la Princesa (IISP), Universidad Autónoma de Madrid, Diego de León 62, 28030 Madrid, Spain. E-mail: jbsoriano2agmail.com

@ERSpublications

Smoking is bad for your lungs; quitting is good, anytime, anyhow http://ow.ly/5KHL30b0YXL

Cite this article as: Wood L, Quint JK, Soriano JB. Smoking cessation and COPD: further evidence is more necessary than ever. Eur Respir J 2017; 49: 1700466 [https://doi.org/10.1183/13993003.00466-2017].

For twelve years I had been trying to give up smoking. As Mark Twain said-and who does not know the remark? - "It's nothing to stop. I've quit a hundred times." I used to feel I had said it myself, for certainly I had tried on ten times ten occasions, once for a year, once for nine months, once for four months. Over and over again I gave them up, a hundred times over the years, but always I went back. For in my dreams, sooner or later, I struck a match, brought flame to the tip, then took in all my hunger for existence with the first puff. I felt impaled on desire itself-those fiends trapped in my chest and screaming for one drag. Change the given!

So I learned what addiction is. A beast had me by the throat and its vitals were in my lungs. I wrestled that devil for twelve years and sometimes I beat him back. Usually it was at great loss to myself, and great loss to others. For when I did not smoke, I grew violent.

Norman Mailer, Tough Guys Don't Dance, 1984.

Many scholars consider the above paragraphs, from a noir thriller and murder-mystery novel [1], to be one of the best descriptions in literature of the withdrawal syndrome experienced by many smokers who try to quit. It is unknown whether Tim Madden, its main character, had chronic obstructive pulmonary disease (COPD), as case-finding spirometry was mostly non-existent during the 1980s. In all likelihood he did, as any chain-smoker might [2]. In this issue of the European Respiratory Journal, JosEPHS et al. [3] report on a large cohort of COPD patients constructed from the Hampshire Health Record Analytical Database (HHRA). They conclude that COPD patients who became ex-smokers had significantly better health outcomes than continuous smokers in terms of reduced mortality and use of health services (hospitalisations and emergency room visits), emphasising the importance of effective smoking-cessation support regardless of age or lung function.

There are numerous strengths to this HHRA research given its real-world nature, including the utilisation of routinely recorded clinical data to delineate a cohort of individuals with COPD who experienced the complexities of living with such a condition. Here, the authors explore the effectiveness of smoking cessation in real-life, with the usual smoking temptations and habitual triggers, alongside any number of comorbidities and with none of the incentives one might find in a randomised clinical trial. In particular, the HHRA links both primary and secondary care data together, to provide more reliable estimates of

Received: March 062017 | Accepted: March 062017

Conflict of interest: Disclosures can be found alongside this article at erj.ersjournals.com

Copyright @ERS 2017 
hospital care contact than routinely recorded in primary care after discharge. Additionally, the authors employ a validated method for defining their COPD cohort, based on Read diagnostic codes [4], using codes indicative of smoking status which were recorded close to the start of the study.

However, a number of limitations must be stressed, some of them already identified by the authors. The collection of routine clinical data is not passive, but often motivated by financial incentives such as those set out by the "Quality and Outcomes Framework" [5] to define the COPD condition since 2004. Furthermore, these incentives change with time, encouraging clinicians to record diagnoses in different ways. Indeed, the authors found that data relating to smoking pack-years and time since quitting were simply not recorded, and therefore could not be accounted for in the analysis. As such, it is worth highlighting that this "real-world" setting cannot necessarily be generalised to the entirety of the UK, or to elsewhere, as the completeness of the smoking information could be better. Many smokers may not always be honest about whether or not they are still smoking and, furthermore, General Practitioners (GPs) and other health workers may not use every encounter as an opportunity to ask. For instance, smokers often think that if they have significantly cut down then this is as good as quitting. In addition, depending upon how you phrase the question their answer changes and this is why biomarkers such as cotinine or exhaled carbon monoxide are needed to validate smoking status. Encouraging all healthcare professionals to use every opportunity to ask and promote quitting is important.

As with all observational research, unrecorded information may confound results despite multivariable adjustment for factors thought to be important at the time of the study. Over-adjustment is always an issue but, on balance, when results are logical and consistent with the existing literature, one must acknowledge the overall benefit of examining the effect of smoking cessation in a typical COPD patient as well as in "any smoker".

It is rather odd that, two generations after the seminal book by FLETCHER et al. [6] (which was summarised by two of the original authors in just four pages a year later in what became an infamous paper [7]), we are still struggling to objectively determine the benefits of smoking cessation in respiratory patients. Any research on lung function change over time is difficult, but to tie this to smoking status is even more difficult, and more evidence is indeed more necessary than ever.

All in all it is estimated that there are 933 million daily smokers in the World [8]. Despite a number of laudable recent successes in some Western countries, including the introduction of plain packaging [9] (figure 1), the World Health Organization/University of Washington "Global Burden of Disease" study is a

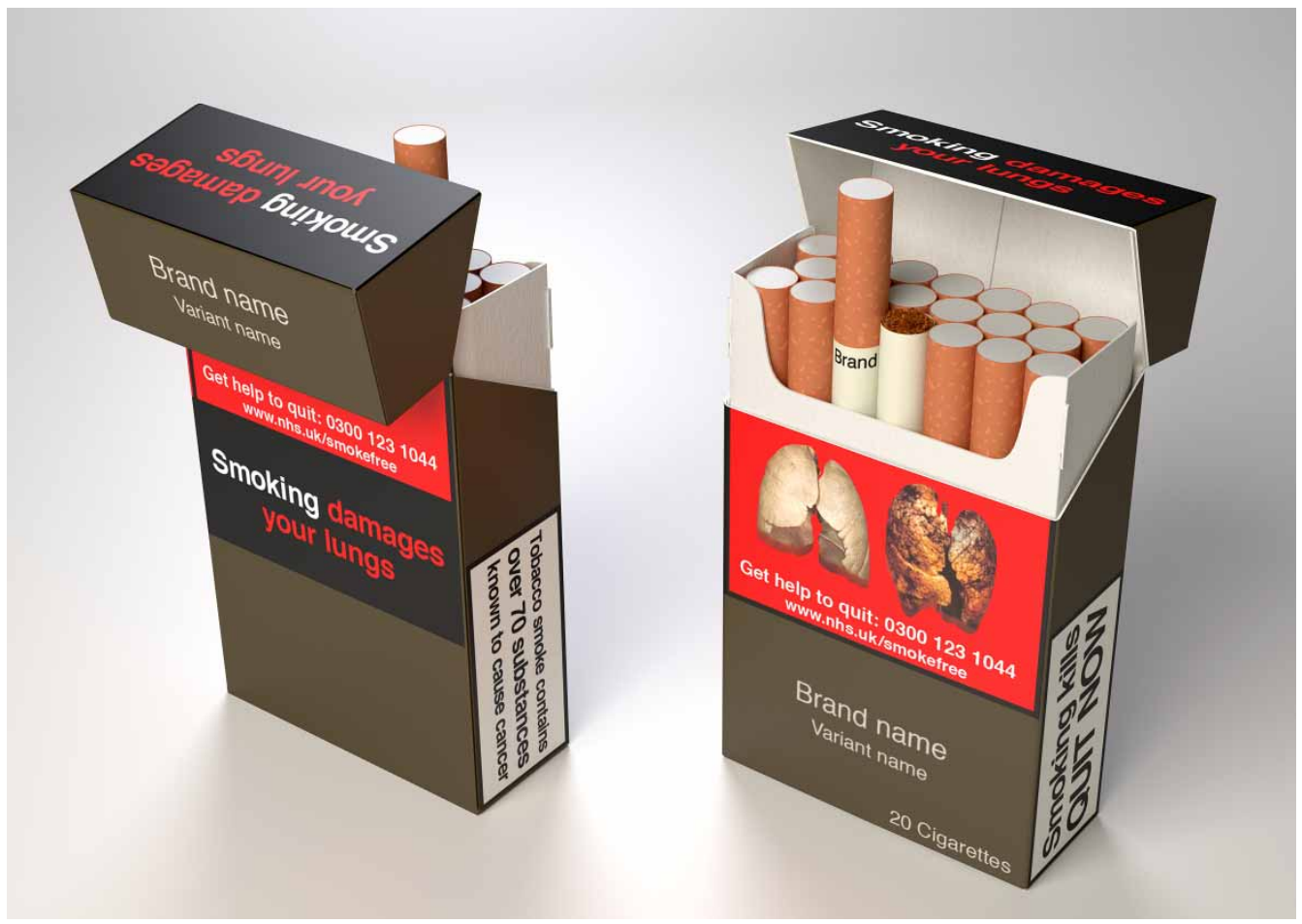

FIGURE 1 Plain packaging for cigarettes with examples of warning labels that graphically depict some of the possible effects of smoking. Reproduced from [9] with permission under the Open Government Licence v.1.0. 
gentle reminder to all that globally in 2015 the age-standardised prevalence of daily smoking was $25.0 \%$ for men and $5.4 \%$ for women. On the one hand, China, India and Indonesia (the three leading countries by total number of male smokers) accounted for $51.4 \%$ of the world's male smokers in 2015 . On the other hand, the USA, China and India, (the three leading countries by total number of female smokers) accounted for only $27.3 \%$ of the world's female smokers [10]. There are more smokers now than ever before in history.

The findings of this study support the need to continue investment in these services elsewhere in Europe, both to improve patient care and to reduce the pressures on health services from patients with COPD. The secular nihilism surrounding any respiratory research, both from policy makers and physicians, should not occur again in the 21st century [11]. As recently highlighted [12], positive collaboration, being helpful when refereeing colleagues' submissions for funding, and the ability to speak with one voice are winning strategies to increase respiratory and COPD research yield [13]. For the benefit of our patients, achieving eradication targets of less than $5 \%$ of daily smokers by 2050 [14] will require the coordinated help and collaboration of all concerned.

\section{References}

Mailer N. In: Tough Guys Don’t Dance. New York, Random House, 1984.

2 Lundbäck B, Lindberg A, Lindström M, et al. Not 15 but $50 \%$ of smokers develop COPD?--Report from the Obstructive Lung Disease in Northern Sweden Studies. Respir Med 2003; 97: 115-122.

3 Josephs L, Culliford D, Johnson M, et al. Improved outcomes in ex-smokers with COPD: a UK primary care observational cohort study. Eur Respir J 2017; 49: 1602114.

4 Quint JK, Müllerova H, DiSantostefano R, et al. Validation of chronic obstructive pulmonary disease recording in the Clinical Practice Research Datalink (CPRD-GOLD). BMJ Open 2014; 4: e005540.

5 Roland M, Guthrie B. Quality and outcomes framework: what have we learnt? BMJ 2016; 354: i4060.

6 Fletcher C, Peto R, Tinker C, et al. The natural history of chronic bronchitis and emphysema. Oxford, Oxford University Press, 1976.

7 Fletcher C, Peto R. The natural history of chronic airflow obstruction. BMJ 1977; 1: 1645-1648.

8 Esson KM, Leeder SR. The Millennium development goals and tobacco control: an opportunity for global partnership. Geneva, World Health Organization, 2004. www.who.int/tobacco/publications/mdg_final_for_web.pdf Date last accessed: April 202017.

9 Department of health. Government backs standardised packaging of tobacco. www.gov.uk/government/uploads/ system/uploads/attachment_data/file/323980/Image_of_standardised_pack_for_consultation.jpg Date last updated: January 21 2015. Date last accessed: May 082017.

10 GBD 2015 Tobacco Collaborators. Estimating smoking prevalence and attributable disease burden in 195 countries and territories, 1990-2015: a systematic analysis from the Global Burden of Disease Study 2015. Lancet 2017; in press [http://dx.doi.org/10.1016/S0140-6736(17)30819-X] Date online: April 05 2017. Date last accessed: April 202017.

11 Burney P. Chronic respiratory disease-the acceptable epidemic? Clin Med (Lond) 2017; 17: 29-32

12 Snell N, Jarrold I, Holgate S. The current state of respiratory research in the UK. Thorax 2015; 70: 1011-1013.

13 Soriano JB, Paton J, Martin Burrieza F, et al. The ERS Research Agency: the beginning. Eur Respir J 2016; 47: 1017-1023.

14 Malone RE. The Race to a tobacco endgame. Tob Control 2016; 25: 607-608. 